\title{
Awareness on the possible adverse effects of Garcinia cambogia: A scientific approach
}

\author{
James H. Zothantluanga ${ }^{1}$, Hannah S. Lalnunpuii ${ }^{2}$, Hans Raj Bhat ${ }^{1}$, Anshul Shakya ${ }^{*}$ \\ ${ }^{1}$ Department of Pharmaceutical Sciences, Faculty of Science and Engineering, Dibrugarh University, Dibrugarh 786004, Assam, India \\ ${ }^{2}$ Assam Medical College and Hospital, Dibrugarh 786002, Assam, India
}

\begin{abstract}
The modern popular ideology is that plant-based products do not have adverse effects. Hence, people are fond of using herbal products of their choice to treat their own ailments or anyone else. As majority of the population are not aware of herbal toxicity concept, the use of formulated single or combined medicinal and/or nutritional plant extracts or isolated compounds to treat chronic diseases are increasingly popular due to the widespread concerns regarding the adverse effects of pharmaceutical drugs. Awareness from the scientific community to bring society to its senses regarding the safety issue of a herbal product is rare. Garcinia gummigutta (more popularly known by the synonym Garcinia cambogia in commercial preparations), belonging to the family of Clusiaceae (alt. Guttiferae) is a popularly consumed weight-loss nutraceutical. This review aims to highlight the possible adverse effects of G. cambogia. For the said purpose, 147 articles were collected from PubMed, Web of Science and Google scholar. Literature review revealed a plethora of beneficial actions. Investigational outcomes and clinical evidences hint the possible adverse effects likely to be linked with the use of G. cambogia. However, the use of G. cambogia as an anti-obesity agent is advisable as long as the therapeutic value outweighs the adverse effect.
\end{abstract}

Keywords: Garcinia cambogia, Garcinia gummi-gutta, herbal toxicity, nutraceutical, obesity, weight-reducing drug.

\section{Introduction}

Obesity, in simple terms, is defined as a chronic metabolic disorder leading to over-accumulation of fats in the adipose tissue. ${ }^{1}$ Sometimes, obesity is also described as a condition when the body fat is greater than $25 \%$ and $30 \%$ of the total body mass in men and women respectively. ${ }^{2}$ Clinically, obesity is defined as a body mass index (BMI) equal to or greater than $30 \mathrm{~kg} / \mathrm{m}^{23,4}$ As per $\mathrm{BMl}$, obesity is further classified as class 1 obesity $\left(30.0-34.9 \mathrm{~kg} / \mathrm{m}^{2}\right)$, class 2 obesity $\left(35.0-39.9 \mathrm{~kg} / \mathrm{m}^{2}\right)$ and class 3 obesity $\left(+40 \mathrm{~kg} / \mathrm{m}^{2}\right)^{5}$

There are two categories of obese individuals, i.e. metabolically healthy obese (MHO) and metabolically unhealthy obese (MUO). ${ }^{6}$ The MUO are more susceptible to develop obesity and related comorbidities. ${ }^{78}$ Whereas, MHO have lesser visceral adiposity, lesser adverse metabolic disturbances and lower cardiovascular risk factors than MUO. Despite these facts, MHO individuals are also still unsafe in comparison to normal-weight individuals. ${ }^{9}$ 
Epidemiologically, the number of people affected by obesity worldwide has doubled within almost a 30-year span, i.e. from 1980 to $2008 .^{2}$ In low-income countries, obesity is highly prevalent in middle-aged people. However, in developed countries, obesity is predominant in kids and teenagers. It is noteworthy that nowadays, even in developing countries, the numbers of obese youngsters are increasing. ${ }^{5}$ Moreover; a study revealed that children are also largely affected by obesity, and could possibly develop metabolic syndromes later in life. ${ }^{10}$ Obesity in poor countries is linked with higher education. ${ }^{11}$ Obesity in rich countries is linked with poor living standards and low-quality education. ${ }^{12,13}$

Obesity is a heterogeneous disorder and induced by a number of factors. Although it is difficult to pinpoint the exact origin due to countless mechanisms coming into play, it can, however, be summarised in the following texts. Overconsumption of calorie-dense foods while limiting physical activity is one of the most notable cause for obesity. ${ }^{14,15}$ The consumption of snacks (apart from breakfast, lunch and dinner) in the evening and late at night increases the BMI of an individual and is directly linked with obesity. ${ }^{16}$ Over ingestion of sugars, fats and sodas combined with insufficient intake of dietary fibre, fruits and vegetables is another cause for obesity. In older people, obesity is prevalent with irregular consumption of whole wheat cereals. ${ }^{17} \mathrm{~A}$ study in Iran associates the particular metabolic disorder with a family history of obesity, unusual work timings, sleep deficiency, consumption of psychotropic medicines and the use of other pharmaceuticals particularly those undergoing regular chemotherapy-based treatments. ${ }^{18}$ Menopause is regarded as a high-risk time for weight gain which can further develop to obesity. ${ }^{19} \mathrm{~A}$ study showed that the absence of a specific group of beneficial bacteria called Bacteroidetes in the human gut is linked with obesity. ${ }^{20}$

Obesity is associated with many complex complications. Obesity is damaging to cardiovascular health and contributes to the development of atherosclerosis and acute myocardial infarction. ${ }^{2,16,23}$ Obesity plays a major role in the development of type-2 diabetes. ${ }^{16,21,22}$ Obese individuals are more likely to develop hypertension. ${ }^{24-28}$ Obesity is also associated with infertility, stroke, arthritis, neuroinflammation and hypothyroidism. ${ }^{1,40-32}$

Out of many drugs, there are six commonly prescribed potent antiobesity medications and they all come with a variety of adverse effects. Phentermine causes dry mouth, insomnia, dizziness and irritability. Orlistat causes faecal urgency, oily stool, flatus with discharge and faecal incontinence. Phentermine/topiramate extended-release causes paresthesias, dizziness, dysgeusia, insomnia, constipation and dry mouth. Lorcaserin causes headache, dizziness, fatigue, nausea, dry mouth and constipation. Naltrexone/bupropion sustained- release causes nausea, vomiting, constipation, headache, dizziness, insomnia and dry mouth. Liraglutide causes nausea, vomiting, diarrhoea, constipation, dyspepsia and abdominal pain. ${ }^{33,34}$ Currently, the public are aware of the dangers accompanied with the use of conventional drugs. Nutraceuticals seem to provide a solution for the inevitable adverse effects of pharmaceuticals. Hence the consumption of herbal preparations is one practice followed to evade the harmful effects arising from pharmacotherapy.

Garcinia gummi-gutta (L.) N.Robson, commonly known as Malabar-tamarind or brindleberry, is a member of the family Clusiaceae (alt. Guttiferae), is one such medicinal plant whose fruit rinds are harvested for its antiobesity property. ${ }^{35-37}$ It is still more popularly known by its old scientific name Garcinia cambogia (Gaertn.) Desr. because of widespread use of the name in commercial products. $(-)$-Hydroxycitric acid (HCA, Figure 1) is the main active phytochemical of the fruits of $G$. cambogia. ${ }^{38,39}$ It effectively inhibits ATP citrate lyase which causes a decrease in acetyl-CoA upon which synthesis of fatty acid and lipogenesis are suppressed. ${ }^{40}$ The methanolic extract of G. cambogia was found to contain xanthochymol (Figure 2). ${ }^{41}$ The diethyl ether extract of $G$. cambogia was found to contain garcinol (Figure 3), guttiferone I (Figure 4), guttiferone J (Figure 5), guttiferone $\mathrm{K}$ (Figure 6), guttiferone $M$ (Figure 7), guttiferone N (Figure 8), oxy-guttiferone $\mathrm{K}$ (Figure 9). ${ }^{42}$

HCA is considered to be safe when tested in rats. ${ }^{43} \mathrm{~A}$ novel water-soluble calcium/potassium salt of HCA, i.e. Super CitriMax was found to have relatively high bioavailability and fewer signs of toxicity in rats. ${ }^{44,45}$ G. cambogia has been investigated and proven to be a potent antiobesity agent with weight-reducing efficiency in animal models. ${ }^{46-65}$ A study concluded that G. cambogia inhibited the accumulation of lipids in 3T3-L1 cells. ${ }^{66,67} \mathrm{G}$. cambogia contains phytochemicals which can down-regulate genes linked with obesity. ${ }^{68,69}$

Recent study reported that pear pomace extract and G. cambogia extract jointly prevent adipogenesis and boosted lipolysis in 3T3-L1 cells. ${ }^{70}$ Further, the weight-reducing property of $G$. cambogia had also been clinically validated in humans. ${ }^{71-85}$ The satiety inducing property had also been reported. ${ }^{86}$ Another study reported that the extract obtained from the fruits of Citrus junos accelerates the anti-adipogenic action of G. cambogia. ${ }^{87}$ A combination of physical exercise and G. cambogia is found to increase the endurance of an athlete allowing higher expenditure of calories thereby promoting weight loss. ${ }^{88} \mathrm{~A}$ randomized study in Iraq reported that orlistat in combination with $G$. cambogia rather than orlistat administered alone was found to result in better cardio-metabolic parameters. ${ }^{89}$

Furthermore, in 2002, the antiulcer activity of $G$. cambogia was reported twice. ${ }^{90,91}$ In 2007, anti- 
<smiles>O=C(O)CC(O)(C(=O)O)C(O)C(=O)O</smiles>

Figure 1| (-)-Hydroxycitric acid (HCA).

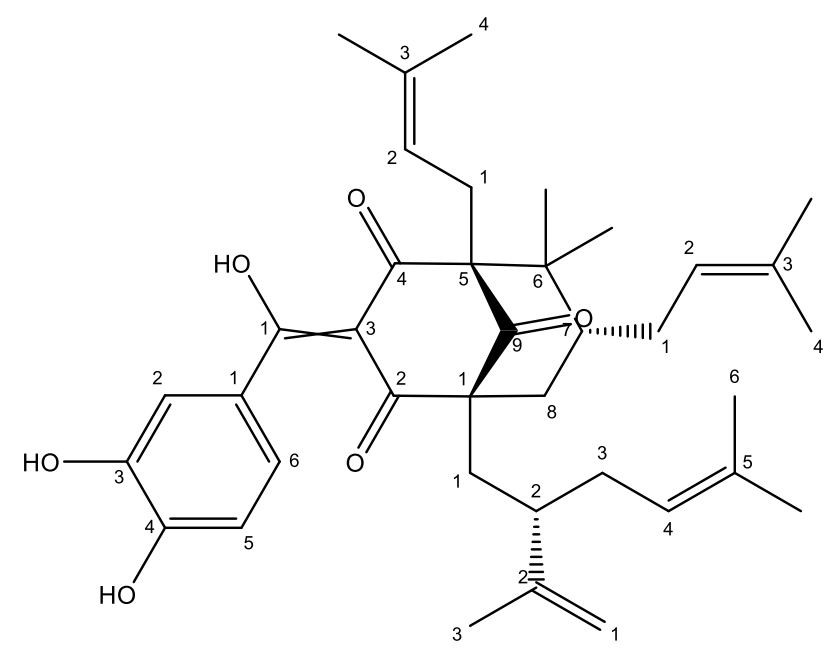

Figure 3 | Garcinol.

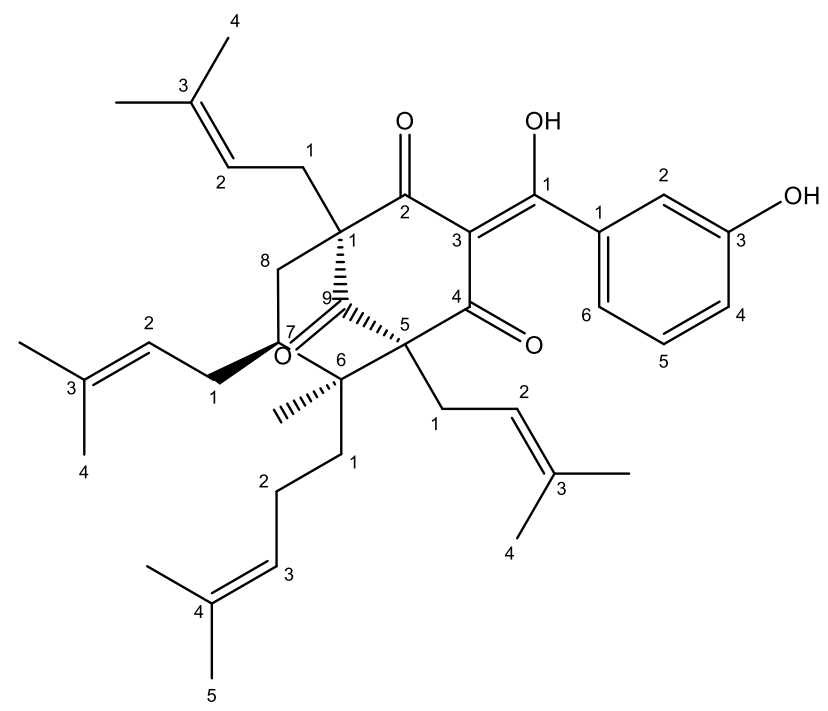

Figure 5 | Guttiferone J.

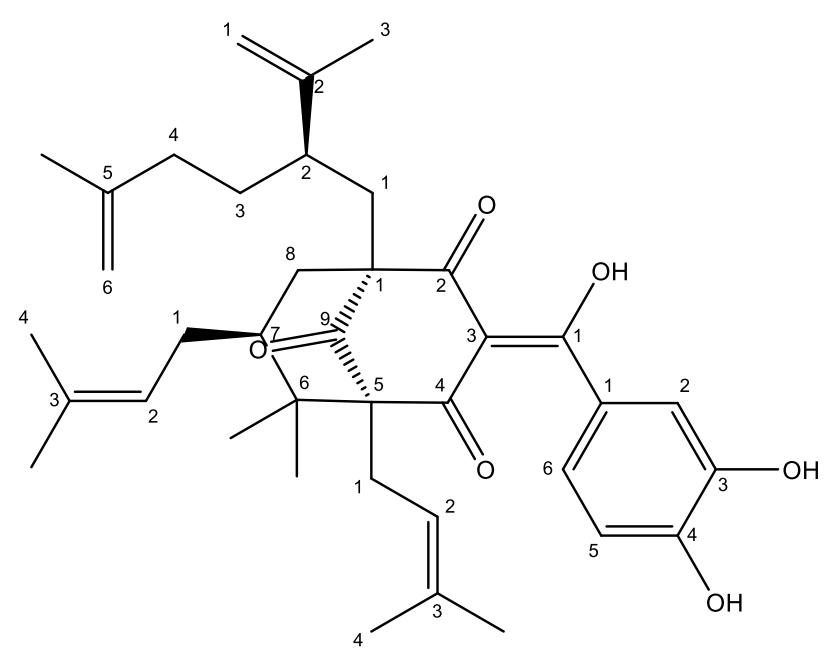

Figure 2 | Xanthochymol.

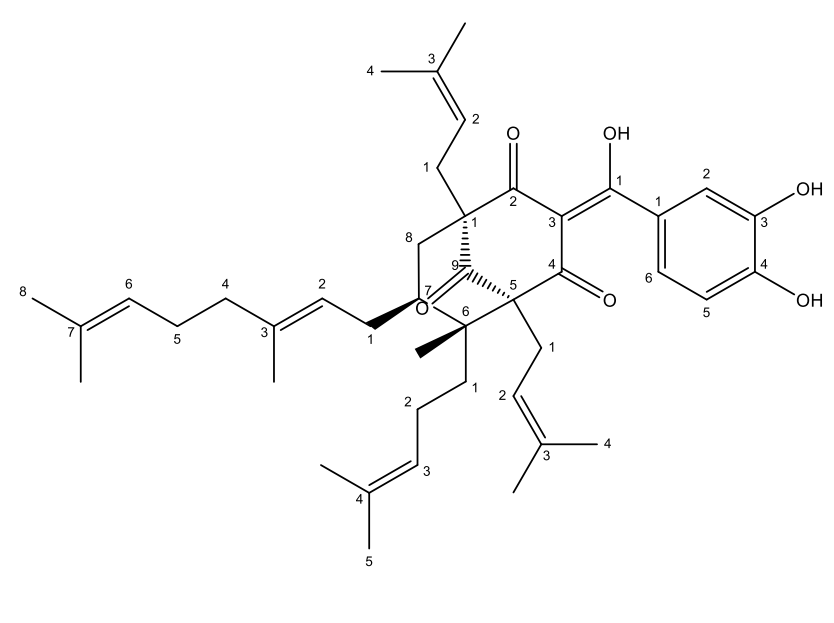

Figure 4 | Guttiferone I.

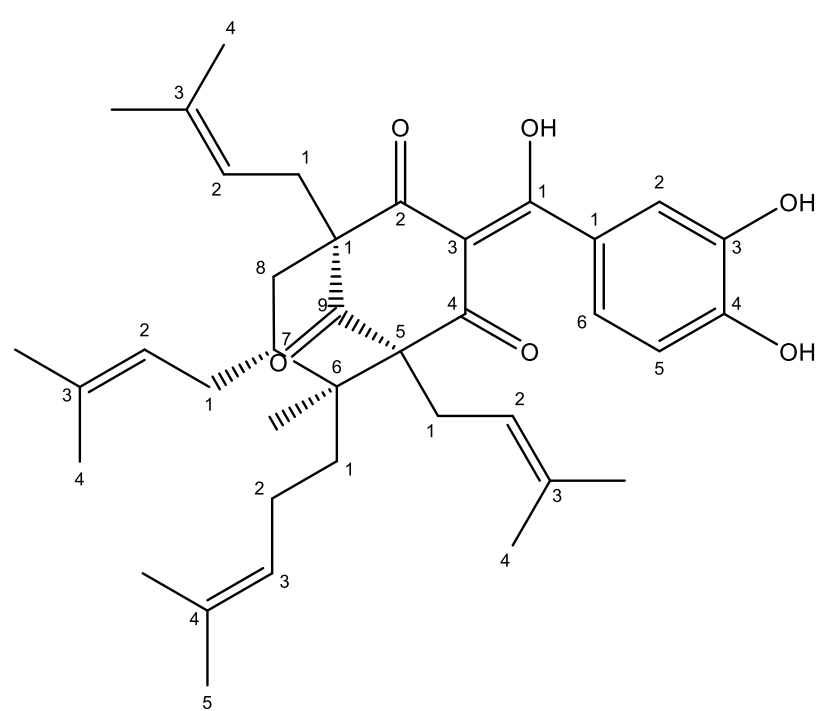

Figure 6 | Guttiferone K. 


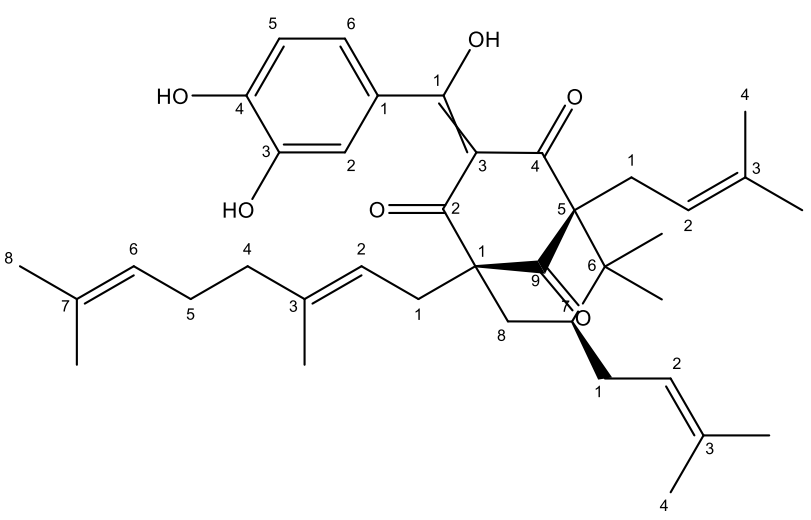

Figure 7 | Guttiferone M.

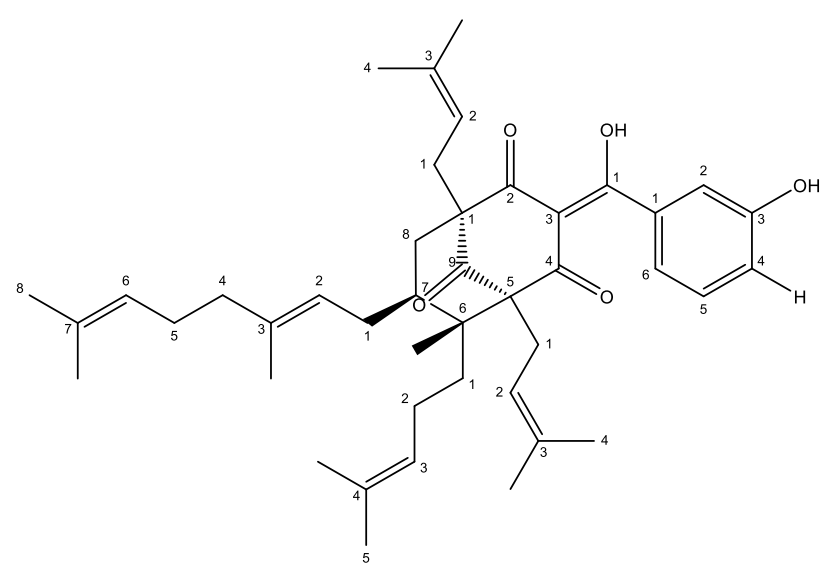

Figure 8 | Guttiferone N.<smiles>CC(C)=CCCC1(C)C2(CC=C(C)C)CC(=O)[C@](CC=C(C)C)(C(=O)c3c2oc2cc(O)c(O)cc2c3=O)C1(C)CC=C(C)C</smiles>

Figure 9 | Oxy-Guttiferone K.

inflammatory activity was first reported. It was again later re-investigated in 2009, 2014 and 2018..$^{59,92-94}$ In 2007, antioxidant activity was first reported. It was again later re-investigated in 2009, 2011 and twice in 2016. ${ }^{59,62,95-98}$ In the year 2009, tumoricidal property was explored and reported. ${ }^{99}$ In 2011, anti-diuretic activity was reported. ${ }^{100} \mathrm{G}$. cambogia was reported to lower insulin resistance and improve glucose metabolism and also displayed suppression of hunger similar to leptin and improves its signalling. ${ }^{101,102} \mathrm{G}$. cambogia lowered blood glucose levels both in animal models as well as in humans. ${ }^{103}$ G. cambogia showed potential for ameliorating phosphorus and copper deficiency in animal model. ${ }^{104} \mathrm{G}$. cambogia effectively ameliorates depleted glycogen levels in human skeletal muscles. ${ }^{105} \mathrm{G}$. cambogia intensifies the release of serotonin from the cortex of the brain of rats. ${ }^{106} A$ study reports that exogenous histamine formation in skipjack was prevented by the addition of $G$. cambogia. ${ }^{107}$ Fresh and immobilized biomass of $G$. cambogia was tested for its arsenic removing property in arsenic-contaminated groundwater and the test results were positive. ${ }^{108}$

The genotoxicity of G. cambogia was investigated by Lee and Lee in 2007 using Ames test, chromosome aberration test and micronucleus test and results showed that $G$. cambogia does not exhibit genotoxicity. ${ }^{109}$ However, the genotoxicity study carried out by Lee and Lee was refuted by Lau et. al. the following year by highlighting several shortcomings in the materials used and methods adopted for evaluation while simultaneously emphasizing on the weakness in statistical analysis. ${ }^{110} \mathrm{G}$. cambogia extract has the potency to inhibit CYP2B6 which is a family of CYP450 enzyme in a timely manner, but HCA alone was not able to significantly inhibit CYP2B6. ${ }^{111}$

Few contradictory reports were also retrieved, suggesting that $G$. cambogia is not as effective in weight lowering property as it is claimed to be. ${ }^{77,112-}$ 120 None the less, many herbal based companies are 
having preparations of $G$. cambogia that are currently on the global market. ${ }^{76,121-123}$ As a result of the immense hype of the weight-reducing potency of the nutraceutical, the adverse effects are going unnoticed and overlooked.

The main aim of this review is therefore to educate the society by highlighting all possible adverse effects of the herbal drug by accessing all of the available research data's and clinical evidences. This article does not aim to discourage anyone from taking the phytomedicine nor disrupt any related business associated with $G$. cambogia. It will rather spread awareness to the masses regarding the lesser -known adverse effects of the nutraceutical.

\section{Materials and Methods}

PubMed, Scopus, Web of Science and Google Scholar were accessed to obtain relevant articles. Articles were explored using 'Garcinia cambogia', 'antiobesity herbal drug', 'weight loss nutraceutical' and 'obesity' as keywords. A total of 147 articles were collected and reviewed. Even though there existed a possibility of compiling the whole profile for the plant like many of the available articles, precautions were taken to maintain the novelty of the review article by focusing on the sole purpose of highlighting only the adverse effects of the nutraceutical. Provisions were made to include all the significant information while excluding all needless texts.

\section{Results and discussion}

The use of herbal nutraceuticals including $G$. cambogia is higher in females when compared to males. $^{124}$ Hence, to spread awareness, scientifically reported adverse effects possibly linked with the use of $G$. cambogia are compiled below.

Rhabdomyolysis was induced in a 54-year-old white female upon the ingestion of a herbal drug named 'body maximizing' where G. cambogia was one of the active ingredients alongside vitamin $E$, magnesium, zinc, chromium, ma huang, guarana, chitosan, Gymnena sylvestre, bee pollen, ginseng root, ginger root, lecithin, damiana root, sarsaparilla root, nettle leaf and royal jelly. The patient's serum creatinine kinase (CK) level was 1028 IU/L (normal range: $26-140 \mathrm{IU} / \mathrm{L}){ }^{125}$

Liver toxicity (hepatitis) related to the use of a herbal product was encountered in two individuals with the intake of a weight loss medication called 'Hydroxycut' whose active ingredients included $G$. cambogia. Liver function test of patient 1 revealed that the levels of aspartate aminotransferase, alanine aminotransferase, bilirubin and alkaline phosphatase were $1808 \mathrm{U} / \mathrm{L}$ (normal range: 5-50 U/L), $3131 \mathrm{U} / \mathrm{L}$ (normal range: $7-40 \mathrm{U} / \mathrm{L}$ ), $7.8 \mathrm{mg} / \mathrm{dL}$ (normal range: $0.0-1.5 \mathrm{mg} / \mathrm{dL}$ ) and $171 \mathrm{U} / \mathrm{L}$ (normal range: $40-150$ $U / L$ ) respectively. In patient 2 , the levels of aspartate aminotransferase, alanine aminotransferase, bilirubin and alkaline phosphatase were $59 \mu / L$ (normal range: 5-50 U/L), $45 \mu / \mathrm{L}$ (normal range: $7-40 \mathrm{U} / \mathrm{L}$ ), $7.8 \mathrm{mg} /$ $\mathrm{dL}$ (normal range: $0.0-1.5 \mathrm{mg} / \mathrm{dL}$ ) and $530 \mu / \mathrm{L}$ (normal range: $40-150 \mathrm{U} / \mathrm{L}$ ) respectively. ${ }^{126}$

A review article cited a case report on the adverse effect of $G$. cambogia as dizziness, increased appetite, dry mouth, palpitation and increased hepatic enzyme that were induced with a dose of 1.2 $\mathrm{g}$ for a period of 3 to 4 days in a 34 and 48 years old female along with one 48 years old male. The same article cited adverse effects reported from clinical trials of $G$. cambogia as nausea and headache induced with a dose of $1.26 \mathrm{~g}$ for a period of 4 weeks; headache, upper respiratory tract symptoms and gastrointestinal symptoms induced with a dose of $3 \mathrm{~g}$ for a period of 12 weeks; common cold, toothache and diarrhoea induced with a dose of 1.7 $\mathrm{g}$ for 12 weeks; nausea and headache induced with a dose of $1.5 \mathrm{~g}$ for a period of 8 weeks. ${ }^{127}$ Further, one of the report suggested that HCA causes marked testicular toxicity and impaired spermatogenesis in Zucker obese rats at a daily dose of $778 \mathrm{mg} / \mathrm{kg}$ b.w. and $1244 \mathrm{mg} / \mathrm{kg} \mathrm{b.w.}{ }^{56}$

A 45-year-old obese female suffering from chronic asthma died due to liver failure that had been taking montelukast for the past 5 years and had also previously completed a 7-day course with two herbal supplements wherein G. cambogia was an active ingredient in one of the herbal product. As the patient was admitted to hospital with jaundice, the authors made a highly speculative statement that montelukast or $G$. cambogia alone would not be responsible for the patient's death but it might rather be a synergistic action of the two. ${ }^{128}$

A 19-year-old soldier deployed to Iraq had the symptoms of nausea, vomiting and jaundice following the consumption of Hydroxycut. ${ }^{129}$

A study was conducted using $\mathrm{C} 57 \mathrm{BL} / 6 \mathrm{~J}$ mice. The study revealed that $G$. cambogia resulted in increased accumulation of collagen and lipid peroxidation. The levels of aspartate aminotransferase and alanine aminotransferase, proinflammatory markers such as TNF- $\alpha$ and MCP-1, hepatic superoxide dismutase and glutathione peroxidase were also increased. ${ }^{55}$ The study carried out on $\mathrm{C} 57 \mathrm{BL} / 6 \mathrm{~J}$ mice were refuted by Clouatre et al. by questioning the incompleteness of the study. The form of HCA that was not indicated was questioned. A statement was made regarding the source of toxicity. The animal model chosen for the study was also considered inappropriate. The information regarding the test compound was regarded as incomplete. ${ }^{130}$ In the light of the statement made by Clouatre et al., the authors of this article would also like to mention that the anti-inflammatory and antioxidant activity were already positively assessed. ${ }^{59,62,92-98}$

On sub-acute consumption of $G$. cambogia extract for about 18 days, the serum troponin levels 
of a 48-year-old woman was elevated. Acute necrotizing eosinophilic myocarditis resulted in heart failure requiring extracorporeal membrane oxygenation. ${ }^{131}$ Further, sub-chronic consumption of G. cambogia along with selective serotonin reuptake inhibitors namely escitalopram and sertaline for 2-3 months, a 35-year-old woman developed serotonin toxicity. $^{132}$

A week after the consumption of G. cambogia, the levels of alanine aminotransferase, aspartate aminotransferase, alkaline phosphatase and ferritin of a 42-year-old female were $1277 \mathrm{U} / \mathrm{L}$ (normal range: $7-40 \mathrm{U} / \mathrm{L}), 2792 \mathrm{U} / \mathrm{L}$ (normal range: 5-50 U/L), $283 \mathrm{U} / \mathrm{L}$ (normal range: 40-150 U/L) and 12,198 $\mathrm{mcg} / \mathrm{L}$ (normal range: $11-307 \mathrm{mcg} / \mathrm{L}$ ) respectively. ${ }^{133}$ The same case was described by Mancano (2015) as awareness to the public regarding drug interactions. $^{134}$

Following the consumption of G. cambogia, the levels of alanine aminotransferase, aspartate aminotransferase and bilirubin of a 52-year-old female were found to be $568 \mathrm{U} / \mathrm{L}$ (normal range: 7$40 \mathrm{U} / \mathrm{L}$ ), $723 \mathrm{U} / \mathrm{L}$ (normal range: 5-50 U/L) and 10.1 $\mathrm{mg} / \mathrm{dL}$ (normal range: $0.0-1.5 \mathrm{mg} / \mathrm{dL}$ ) respectively. The model for end-stage liver disease score that initially was 23 increased to 28 . The authors claimed that $G$. cambogia was liable for the progression of the liver disease. ${ }^{135}$

A 34-year-old Hispanic male required liver transplantation after the intake of $G$. cambogia 3 times a day. ${ }^{136} \mathrm{~A}$ review article that was published in the same year listed G. cambogia among a list of dietary supplements that are hepatotoxic. ${ }^{137}$

A 51-year-old female with a 12-year history of type 1 bipolar disorder started consuming $G$. cambogia and was easily irritated and agitated. ${ }^{138}$

A 33-year-old woman consuming G. cambogia for weight loss had an acute onset of psychomotor retardation, thought broadcasting, flat affect, persecutory delusions and auditory hallucinations. ${ }^{139}$ An article also reviewed different types of herbals having the potential to induce mania wherein $G$. cambogia was included. ${ }^{140}$

A 56-year-old female developed mental confusion with the use of $G$. cambogia at a dose of two tablets taken three times a day. The patient had diabetic ketoacidosis, pancreatitis and elevated troponin levels. $^{141}$

The levels of alanine aminotransferase, aspartate aminotransferase, alkaline phosphatase and bilirubin of a 57-year-old female consuming G. cambogia with no history of liver disorders were $738 \mathrm{U} / \mathrm{L}$ (normal range: $7-40 \mathrm{U} / \mathrm{L}), 856 \mathrm{U} / \mathrm{L}$ (normal range: 5-50 U/L), $80 \mathrm{U} / \mathrm{L}$ (normal range: $40-150 \mathrm{U} / \mathrm{L}$ ) and $2.4 \mathrm{mg} / \mathrm{dL}$ (normal range: $0.0-1.5 \mathrm{mg} / \mathrm{dL}$ ) respectively. ${ }^{142}$

Following the consumption of $G$. cambogia, a 36 year-old female had fatigue, anorexia and jaundice. The levels of alanine aminotransferase, aspartate aminotransferase, alkaline phosphatase and bilirubin were $5615 \mathrm{U} / \mathrm{L}$ (normal range: 7-40 U/L), $5340 \mathrm{U} / \mathrm{L}$ (normal range: 5-50 U/L), $104 \mathrm{U} / \mathrm{L}$ (normal range: 40 $-150 \mathrm{U} / \mathrm{L}$ ), $7.4 \mathrm{mg} / \mathrm{dL}$ (normal range: $0.0-1.5 \mathrm{mg} / \mathrm{dL}$ ) respectively. ${ }^{143}$ Furthermore, two review articles that were published in the same year reviewed and discussed an array of $G$. cambogia induced liver injury. ${ }^{144,145}$

A clinical investigation of a 82-year-old male, after the consumption of $G$. cambogia, revealed that the patient had fats deposited around the pancreas that was well-matched with acute pancreatitis. ${ }^{146}$ Moreover, a report suggested that a 35-year-old female consumed $G$. cambogia and soon developed nausea, headache, dizziness and swelling of the eyes. $^{147}$

The safety of G. cambogia is controversial and not properly established. Therefore, it is advisable for a common man to consider taking precautionary measures as simple as consulting a physician or a pharmacist who is expert in the field of plant-based medicines for one's safety.

\section{Acknowledgement}

Authors are thankful to Library, Dibrugarh University, Dibrugarh for providing the enriched eresources for the adequate search of relevant journals.

\section{Conflict of interest}

The authors declare that there are no known conflicts of interest with regards to this work.

\section{Declaration of authors' contribution}

All the authors have contributed their time and effort equally.

\section{References}

1. Liu, Y. \& Ding, Z. (2017). Obesity, a serious etiologic factor for male subfertility in modern society. Reproduction, 154, 123-131. DOI: 10.1530/ REP-17-0161.

2. Roberson, L.L., Aneni, E.C., Maziak, W., Agatston, A., Feldman, T., Rouseff, M., Tran, T., Blaha, M.J., Santos, R.D., Sposito, A., Al-Mallah, M.H., Blankstein, R., Budoff, M.J. \& Nasir, K. (2014). Beyond BMI: the "metabolically healthy obese" phenotype \& its association with clinical/ subclinical cardiovascular disease and all-cause mortality - a systematic review. BioMed Central Public Health, 14, 14. DOI: 10.1186/1471-2458-14-14.

3. Qasim, A., Turcotte, M., de Souza, R.J., Samaan, M.C., Champredon, D., Dushoff, J., Speakman, J.R. \& Meyre, D. (2018). On the origin of obesity: identifying the biological, environmental and 
cultural drivers of genetic risk among human populations. Obesity Reviews, 19, 121-149. DOI: 10.1111/obr.12625.

4. Craig, J.R., Jenkins, T.G., Carrell, D.T. \& Hotaling, J.M. (2017). Obesity, male infertility, and the sperm epigenome. Fertility and Sterility, 107, 848-859. DOI: 10.1016/j.fertnstert.2017.02.115.

5. Engin, A. (2017). The definition and prevalence of obesity and metabolic syndrome. Advances in Experimental Medicine and Biology, 960, 1-17. DOI: 10.1007/978-3-319-48382-5_1

6. Dobson, R., Burgess, M.I., Sprung, V.S., Irwin, A., Hamer, M., Jones, J., Daousi, C., Adams, V., Kemp, G.J., Shojaee-Moradie, F., Umpleby, M. \& Cuthbertson, D.J. (2016). Metabolically healthy and unhealthy obesity: differential effects on myocardial function according to metabolic syndrome, rather than obesity. International Journal of Obesity, 40, 153-161. DOI: 10.1038/ijo.2015.151.

7. Goncalves, C.G., Glade, M.J. \& Meguid, M.M. (2016). Metabolically healthy obese individuals: key protective factors. Nutrition, 32, 14-20. DOI: 10.1016/j.nut.2015.07.010

8. Hwang, Y.C., Hayashi, T., Fujimoto, W.Y., Kahn, S.E., Leonetti, D.L., McNeely, M.J. \& Boyko, E.J. (2015). Visceral abdominal fat accumulation predicts the conversion of metabolically healthy obese subjects to an unhealthy phenotype. International Journal of Obesity, 39, 1365-1370. DOI: 10.1038/ijo.2015.75.

9. Goossens, G.H. (2017). The metabolic phenotype in obesity: fat mass, body fat distribution, and adipose tissue function. Obesity Facts, 10, 207-215. DOI: $10.1159 / 000471488$.

10. Styne, D.M., Arslanian, S.A., Connor, E.L., Farooqi, I.S., Murad, M.H., Silverstein, J.H. \& Yanovski, J.A. (2017). Paediatric obesity assessment, treatment, and prevention: an endocrine society clinical practice guideline. The Journal of Clinical Endocrinology and Metabolism, 102, 709-757. DOI: 10.1210/jc.2016-2573.

11. Kinge, J.M., Strand, B.H., Vollset, S.E. \& Skirbekk, V. (2015). Educational inequalities in obesity and gross domestic product: evidence from 70 countries. Journal of Epidemiology and Community Health，69，1141-1146. DOI: 10.1136/jech-2014205353.

12. Samal, S., Panigrahi, P. \& Dutta, A. (2015). Social epidemiology of excess weight and central adiposity in older Indians: analysis of study on global ageing and adult health. British Medical Journal Open, 5, e008608. DOI: 10.1136/bmjopen-

\section{5-008608.}

13. Levine, J.A. (2011). Poverty and obesity in the U.S. Diabetes, 60, 2667-2678. DOI: 10.2337\%2Fdb111118.

14. Finlayson, G. (2017). Food addiction and obesity: unnecessary medicalization of hedonic overeating. Nature Reviews Endocrinology, 13, 493-498. DOI: 10.1038/nrendo.2017.61.

15. Barrington, W.E. \& Beresford, S.A.A. (2019). Eating occasions, obesity and related behaviours in working adults: does it matter when you snack? Nutrients, 11, 1-13. DOI: 10.3390/nu11102320.

16. Hernandez-Angeles, C. \& Castelo-Branco, C. (2016). Cardiovascular risk in climacteric women: focus on diet. Climacteric, 19, 215-221. DOI: 10.3109/13697137.2016.1173025.

17. Silveira, E.A.D., Vieira, L.L., Jardim, T.V. \& Souza, J.D. (2016). Obesity and its association with food consumption, diabetes mellitus, and acute myocardial infarction in the elderly. Arquivos Brasileiros De Cardiologia, 107, 509-517. DOI: 10.5935\%2Fabc.20160182.

18. Hajian-Tilaki, K.O. \& Heidari, B. (2007). Prevalence of obesity, central obesity and the associated factors in urban population aged 20-70 years, in the north of Iran: a population-based study and regression approach. Obesity Reviews, 8, 3-10. DOI: 10.1111/j.1467-789X.2006.00235.x.

19. Khandelwal, S. (2019). Obesity in midlife: lifestyle and dietary strategies. Climacteric, 2, 1-8. DOI: 10.1080/13697137.2019.1660638.

20. Ley, R.E., Turnbaugh, P.J., Klein, S. \& Gordon, J.I. (2006). Microbial ecology: human gut microbes associated with obesity. Nature, 444, 1022-1023. DOI: $10.1038 / 4441022 a$.

21. Ding, G.L., Liu, Y., Liu, M.E., Pan, J.X., Guo, M.X., Sheng, J.Z. \& Huang, H.F. (2015). The effects of diabetes on male fertility and epigenetic regulation during spermatogenesis. Asian Journal of Andrology, 17, 948-953. DOI: 10.4103/1008$682 X .150844$.

22. Volaco, A., Cavalcanti, A.M., Filho, R.P. \& Precoma, D.B. (2018). Socioeconomic status: the missing link between obesity and diabetes mellitus? Current Diabetes Review, 14, 321-326. DOI: $10.2174 / 1573399813666170621123227$.

23. Flora, G.D. \& Nayak, M.K. (2019). A brief review of cardiovascular diseases, associated risk factors and current treatment regimes. Current Pharmaceutical Design. DOI: $10.2174 / 1381612825666190925163827$. 
24. Scholze, J. \& Sharma, A.M. (2001). Treatment of hypertension in obesity. Herz, 26, 209-221. DOI: 10.1007/pl00002023.

25. Becton, L.J. \& Shatat, I.F., Flynn, J.T. (2012). Hypertension and obesity: epidemiology, mechanisms and clinical approach. Indian Journal of Pediatrics, 79, 1056-1061. DOI: 10.1007/s12098012-0777-x.

26. Hall, J.E., do Carmo, J.M., da Silva, A.A., Wang, Z. \& Hall, M.E. (2012). Obesityinduced hypertension: interaction of neurohumoral and renal mechanisms. Indian Journal of Pediatrics, 79, 1056-1061. DOI: 10.1161/ CIRCRESAHA.116.305697.

27. Seravalle, G. \& Grassi, G. (2017). Obesity and hypertension. Pharmacological Research, 122, 1-7. DOI: 10.1016/j.phrs.2017.05.013.

28. Belyavskiy, E., Pieske-Kraigher, E. \& Tadic, M. (2019). Obstructive sleep apnea, hypertension, and obesity: a dangerous triad. Journal of Clinical Hypertension, DOI: 10.1111/jch.13688.

29. Davidson, L.M., Millar, K., Jones, C., Fatum, M. \& Coward, K. (2015). Deleterious effects of obesity upon the hormonal and molecular mechanisms controlling spermatogenesis and male fertility. Human Fertility, 18, 184-193. DOI: 10.3109/14647273.2015.1070438.

30. Lainez, N.M. \& Coss, D. (2019). REVIEW: obesity, neuroinflammation and reproductive function. Endocrinology, pii: en.2019-00487. DOI: 10.1210/ en.2019-00487.

31. McPherson, N.O. \& Lane, M. (2015). Male obesity and subfertility, is it really about increased adiposity? Asian Journal of Andrology, 17, 450-458. DOI: 10.4103\%2F1008-682X.148076.

32. Aiceles, V. \& da Fonte Ramos, C. (2016). A link between hypothyroidism, obesity and male reproduction. Hormone Molecular Biology and Clinical Investigation, 25, 5-13. DOI: 10.1515/hmbci2015-0054.

33. Saunders, K.H., Umashanker, D., Igel, L.I., Kumar, R.B. \& Aronne, L.J. (2018). Obesity Pharmacotherapy. Medical Clinics of North America, 102, 135-148. DOI: 10.1016/ j.mcna.2017.08.010.

34. Velazquez, A. \& Apovian, C.M. (2018). Pharmacological management of obesity. Minerva Endocrinologica, 43, 356-366. DOI: 10.23736/S03911977.17.02654-2.

35. Semwal, R.B., Semwal, D.K., Vermaak, I. \& Viljoen, A. (2015). A comprehensive scientific overview of Garcinia cambogia. Fitoterapia, 102, 134-
148. DOI: 10.1016/j.fitote.2015.02.012.

36. Astell, K.J., Mathai, M.L. \& Su, X.Q. (2013). A review on botanical species and chemical compounds with appetite suppressing properties for body weight control. Plant Foods for Human Nutrition, 68, 213-221. DOI: 10.1007/s11130-0130361-1.

37. Joyal, SV. (2004). A perspective on the current strategies for the treatment of obesity. Current Drug Targets - CNSE Neurological Disorders, 3, 341356. DOI: $10.2174 / 1568007043336978$.

38. Jena, B.S., Jayaprakasha, G.K., Singh, R.P. \& Sakariah, K.K. (2002). Chemistry and biochemistry of (-)-hydroxycitric acid from Garcinia. Journal of Agricultural and Food Chemistry, 50, 10-22. DOI: 10.1021/jf010753k.

39. Shara, M., Ohia, S.E., Schmidt, R.E., Yasmin, T., Zardetto Smith, A., Kincaid, A., Bagchi, M., Chatterjee, A., Bagchi, D. \& Stohs, S.J. (2004). Physico-chemical properties of a novel (-)hydroxycitric acid extract and its effect on body weight, selected organ weights, hepatic lipid peroxidation and DNA fragmentation, hematology and clinical chemistry, and histopathological changes over a period of 90 days. Molecular and Cellular Biochemistry, 260, 171186. DOI: 10.1023/b:mcbi.0000026069.53960.75.

40. Yamada, T., Hida, H. \& Yamada, Y. (2007). Chemistry, physiological properties, and microbial production of hydroxycitric acid. Applied Microbiology and Biotechnology, 75, 977-982. DOI: 10.1007/s00253-007-0962-4.

41. Chattopadhyay, S.K. \& Kumar, S. (2006). Identification and quantification of two biologically active polyisoprenylated benzophenones xanthochymol and isoxanthochymol in Garcinia species using liquid chromatography-tandem mass spectrometry. Journal of Chromatography B, 844, 67-83. DOI: 10.1016/j.jchromb.2006.07.045.

42. Masullo, M., Bassarello, C., Suzuki, H., Pizza, C. \& Piacente, S. (2008). Polyisoprenylated benzophenones and an unusual polyisoprenylated tetracyclic xanthone from the fruits of Garcinia cambogia. Journal of Agricultural and Food Chemistry, 56, 5205-5210. DOI: 10.1021/jf800416j.

43. Ohia, S.E., Opere, C.A., LeDay, A.M., Bagchi, M., Bagchi, D. \& Stohs, S.J. (2002). Safety and mechanism of appetite suppression by a novel hydroxycitric acid extract (HCA-SX). Molecular and Cellular Biochemistry, 238, 89-103. DOI: 10.1023/ a:1019911205672. 
44. Soni, M.G., Burdock, G.A., Preuss, H.G., Stohs, S.J., Ohia, S.E. \& Bagchi, D. (2004). Safety assessment of (-)-hydroxycitric acid and Super CitriMax, a novel calcium/potassium salt. Food and Chemical Toxicology, 42, 1513-1529. DOI: 10.1016/ j.fct.2004.04.014.

45. Downs, B.W., Bagchi, M., Subbaraju, G.V., Shara, M.A., Preuss, H.G. \& Bagchi, D. (2005). Bioefficacy of a novel calcium-potassium salt of (-)hydroxycitric acid. Mutation Research, 579, 149-162. DOI: 10.1016/j.mrfmmm.2005.02.021.

46. Kim, K.Y., Lee, H.N., Kim, Y.J. \& Park, T. (2008). Garcinia cambogia extract ameliorates visceral adiposity in C57BL/6J mice fed on a high-fat diet. Bioscience, Biotechnology and Biochemistry, 72, 17721780. DOI: $10.1271 / \mathrm{bbb} .80072$.

47. Kim, J., Kyung, J., Kim, D., Choi, E.K., Bang, P., Park, D. \& Kim, Y.B. (2012). Anti-obesity effects of Rapha diet巴 preparation in mice fed on a high-fat diet. Laboratory Animal Research, 28, 265-271. DOI: 10.5625\%2Flar.2012.28.4.265.

48. Ishihara, K., Oyaizu, S., Onuki, K., Lim, K. \& Fushiki, T. (2000). Chronic (-)-hydroxycitrate administration spares carbohydrate utilization and promotes lipid oxidation during exercise in mice. Journal of Nutrition, 130, 2990-2995. DOI: 10.1093/ jn/130.12.2990.

49. Yimam, M., Jiao, P., Hong, M., Brownell, L., Lee, Y.C., Hyun, E.J., Kim, H.J., Kim, T.W., Nam, J.B., Kim, M.R. \& Jia, Q. (2019). Evaluation of natural product compositions for appetite suppression. Journal of Dietary Supplements, 16, 86-104. DOI: 10.1080/19390211.2018.1429518.

50. Vasudeva, N., Yadav, N. \& Sharma, S.K. (2012). Natural products: a safest approach for obesity. Chinese Journal of Integrative Medicine, 18, 473-480. DOI: 10.1007/s11655-012-1120-0.

51. Mahendran, P. \& Devi, C.S. (2001). Effect of Garcinia cambogia extract on lipids and lipoprotein composition in dexamethasone administered rats. Indian Journal of Physiology and Pharmacology, 45, 345-350. PMID: 11881574.

52. Shara, M., Ohia, S.E., Yasmin, T., Zardetto-Smith, A., Kincaid, A., Bagchi, M., Chatterjee, A., Bagchi, D. \& Stohs, S.J. (2003). Dose- and time-dependent effects of a novel (-)-hydroxycitric acid extract on body weight, hepatic and testicular lipid peroxidation, DNA fragmentation and histopathological data over a period of 90 days. Molecular and Cellular Biochemistry, 254, 339-346. DOI: 10.1023/a:1027358106407.

53. Sripradha, R. \& Magadi, S.G. (2015). Efficacy of Garcinia cambogia on body weight, inflammation and glucose tolerance in high fat fed male Wistar rats. Journal of Clinical and Diagnostic Research, 9, 14. DOI: 10.7860/JCDR/2015/12045.5577.

54. Oluyemi, K.A., Omotuyi, I.O., Jimoh, O.R., Adesanya, O.A., Saalu, C.L. \& Josiah, S.J. (2007). Erythropoietic and anti-obesity effects of Garcinia cambogia (bitter kola) in Wistar rats. Biotechnology and Applied Biochemistry, 46, 69-72. DOI: 10.1042/ BA20060105.

55. Kim, Y.J., Choi, M.S., Park, Y.B., Kim, S.R., Lee, M.K. \& Jung, U.J. (2013). Garcinia cambogia attenuates diet-induced adiposity but exacerbates hepatic collagen accumulation and inflammation. World Journal of Gastroenterology, 19, 4689-4701. DOI: 10.3748/wjg.v19.i29.4689.

56. Saito, M., Ueno, M., Ogino, S., Kubo, K., Nagata, J. \& Takeuchi, M. (2005). High dose of Garcinia cambogia is effective in suppressing fat accumulation in developing male Zucker obese rats, but highly toxic to the testis. Food and Chemical Toxicology, 43, 411-419. DOI: 10.1016/ j.fct.2004.11.008.

57. Han, J., Li, L., Wang, D. \& Ma, H. (2016). (-)Hydroxycitric acid reduced fat deposition via regulating lipid metabolism-related gene expression in broiler chickens. Lipids in Health and Disease, 15, 37. DOI: 10.1186\%2Fs12944-016-0208-5.

58. Kim, Y.J., Kim, K.Y., Kim, M.S., Lee, J.H., Lee, K.P. \& Park, T. (2008). A mixture of the aqueous extract of Garcinia cambogia, soy peptide and L-carnitine reduces the accumulation of visceral fat mass in rats rendered obese by a high fat diet. Genes and Nutrition, 2, 353-358. DOI: 10.1007/s12263-007-0070 -1 .

59. Asghar M., Monjok E., Kouamou G., Ohia S.E., Bagchi D. \& Lokhandwala M.F. (2007). Super CitriMax (HCA-SX) attenuates increases in oxidative stress, inflammation, insulin resistance, and body weight in developing obese Zucker rats. Molecular and Cellular Biochemistry, 304(1-2):93-99. DOI: 10.1007/s11010-007-9489-3.

60. Koshy A.S. \& Vijayalakshmi N.R. (2001). Impact of certain flavonoids on lipid profiles--potential action of Garcinia cambogia flavonoids. Phytotherapy Research, 15(5):395-400. DOI: 10.1002/ptr.725.

61. Heo, J., Seo, M., Park, H., Lee, W.K., Guan, L.L., Yoon, J., Caetano-Anolles, K., Ahn, H., Kim, S.Y., Kang, Y.M., Cho, S. \& Kim, H. (2016). Gut microbiota modulated by probiotics and Garcinia cambogia extract correlate with weight gain and adipocyte sizes in high fat-fed mice. Scientific Reports, 6, 33566. DOI: 10.1038/srep33566. 
62. Amin, K.A., Kamel, H.H. \& Abd-Eltawab, M.A. (2011). The relation of high fat diet, metabolic disturbances and brain oxidative dysfunction: modulation by hydroxycitric acid. Lipids in Health and Disease, 10, 74. DOI: 10.1186/1476-511X-10-74.

63. Han, N., Li, L., Peng, M. \& Ma, H. (2016). (-)Hydroxycitric acid nourishes protein synthesis via altering metabolic directions of amino acids in male rats. Phytotherapy Research, 30, 1316-1329. DOI: 10.1002/ptr.5630.

64. Kaur, G. \& Kulkarni, S.K. (2001). Investigations on possible serotonergic involvement in effects of OB200G (polyherbal preparation) on food intake in female mice. European Journal of Nutrition, 40, 127133. PMID: 11697445

65. Talpur, N., Echard, B.W., Yasmin, T., Bagchi, D. \& Preuss, H.G. (2003). Effects of niacin-bound chromium, maitake mushroom fraction SX and (-)hydroxycitric acid on the metabolic syndrome in aged diabetic Zucker fatty rats. Molecular and Cellular Biochemistry, 252, 369-377. DOI: 10.1023/ a:1025564930088.

66. Hasegawa, N. (2001). Garcinia extract inhibits lipid droplet accumulation without affecting adipose conversion in 3T3-L1 cells. Phytotherapy Research, 15, 172-173. PMID: 11268123.

67. Kim, M.S., Kim, J.K., Kwon, D.Y. \& Park, R. (2004). Anti-adipogenic effects of Garcinia extract on the lipid droplet accumulation and the expression of transcription factor. BioFactors, 22, 193-196. DOI: 10.1002/biof.5520220140.

68. Roy, S., Shah, H., Rink, C., Khanna, S., Bagchi, D., Bagchi, M. \& Sen, C.K. (2007). Transcriptome of primary adipocytes from obese women in response to a novel hydroxycitric acid-based dietary supplement. DNA and Cell Biology, 26, 627639. DOI: $10.1089=$ dna.2007.0617.

69. Roy, S., Rink, C., Khanna, S., Phillips, C., Bagchi, D., Bagchi, M. \& Sen, C.K. (2004). Body weight and abdominal fat gene expression profile in response to a novel hydroxycitric acid-based dietary supplement. Gene Expression Patterns, 11, 251-262. DOI: $10.3727 / 000000003783992289$.

70. Sharma, K., Kang, S., Gong, D., Oh, S.H., Park, E.Y., Oak, M.H. \& Yi, E. (2018). Combination of Garcinia cambogia extract and pear pomace extract additively suppresses adipogenesis and enhances lipolysis in 3T3-L1 cells. Pharmacognosy Magazine, 14, 220-226. DOI: 10.4103/ pm.pm_388_17.

71. Haber, S.L., Awwad, O., Phillips, A., Park, A.E. \& Pham, T.M. (2018). Garcinia cambogia for weight loss. American Journal of Health System Pharmacy, 75, 17-22. DOI: 10.2146/ajhp160915.

72. Egras, A.M., Hamilton, W.R., Lenz, T.L. \& Monaghan, M.S. (2011). An evidence-based review of fat modifying supplemental weight loss products. Journal of Obesity, DOI: $10.1155 / 2011 / 297315$.

73. Preuss, H.G., Rao, C.V., Garis, R., Bramble, J.D., Ohia, S.E., Bagchi, M. \& Bagchi, D. (2004). An overview of the safety and efficacy of a novel, natural (-)-hydroxycitric acid extract (HCA-SX) for weight management. Journal of Medicinal Chemistry, 35, 33-48. PIMD: 18084863.

74. Fassina, P., Scherer-Adami, F., Terezinha-Zani, V., Kasper-Machado, I.C., Garavaglia, J., QuevedoGrave, M.T., Ramos, R. \& Morelo-Dal-Bosco, S. (2015). The effect of Garcinia cambogia as coadjuvant in the weight loss process. Nutricion Hospitalaria, 32, 2400-2408. DOI: 10.3305/ nh.2015.32.6.9587.

75. Mullin, G.E. (2015). Supplements for weight loss: hype or help for obesity? Part III. Nutrition in Clinical Practice, 30, 446-449. DOI: 10.1177/0884533615578918.

76. Yasueda, A., Ito, T. \& Maeda, K. (2013). Review: evidence-based clinical research of anti-obesity supplements in Japan. Immunology, Endocrine and Metabolic Agents in Medicinal Chemistry, 13, 185195. DOI: $10.2174 \% 2 F 1871522213666131118221347$.

77. Rios-Hoyo, A. \& Gutierrez-Salmean, G. (2016). New dietary supplements for obesity: what we currently know. Current Obesity Reports, 5, 262270. DOI: 10.1007/s13679-016-0214-y.

78. Hayamizu, K., Ishii, Y., Kaneko, I., Shen, M., Okuhara, Y., Shigematsu, N., Tomi, H., Furuse, M., Yoshino, G. \& Shimasaki, H. (2003). Effects of Garcinia cambogia (Hydroxycitric Acid) on visceral fat accumulation: a double-blind, randomized, placebo-controlled trial. Current Therapeutic Research, 64, 551-567. DOI: 10.1016/ j.curtheres.2003.08.006.

79. Mattes, R.D. \& Bormann, L. (2000). Effects of (-)hydroxycitric acid on appetitive variables. Physiology \& Behavior, 71, 87-94. DOI: 10.1016/ s0031-9384(00)00321-8.

80. Opala, T., Rzymski, P., Pischel, I., Wilczak, M. \& Wozniak, J. (2006). Efficacy of 12 weeks supplementation of a botanical extract-based weight loss formula on body weight, body composition and blood chemistry in healthy, overweight subjects--a randomised double-blind placebo-controlled clinical trial. European Journal of 
Medical Research, 11, 343-350. PMID: 17052970.

81. Toromanyan, E., Aslanyan, G., Amroyan, E., Gabrielyan, E. \& Panossian, A. (2007). Efficacy of Slim339 in reducing body weight of overweight and obese human subjects. Phytotherapy Research, 21, 1177-1181. DOI: 10.1002/ptr.2231.

82. Vasques, C.A., Rossetto, S., Halmenschlager, G., Linden, R., Heckler, E., Fernandez, M.S. \& Alonso, J.L. (2008). Evaluation of the pharmacotherapeutic efficacy of Garcinia cambogia plus Amorphophalluskonjac for the treatment of obesity. Phytotherapy Research, 22, 1135-1140. DOI: 10.1002/ ptr.2323.

83. Vasques, C.A., Schneider, R., Klein-Junior, L.C., Falavigna, A., Piazza, I. \& Rossetto, S. (2014). Hypolipemic effect of Garcinia cambogia in obese women. Phytotherapy Research, 28, 887-891. DOI: 10.1002/ptr.5076.

84. Chong, P.W., Beah, Z.M., Grube, B. \& Riede, L. (2014). IQP-GC-101 reduces body weight and body fat mass: a randomized, double-blind, placebocontrolled study. Phytotherapy Research, 28, 15201526. DOI: $10.1002 /$ ptr.5158.

85. Maia-Landim, A., Ramirez, J.M., Lancho, C., Poblador, M.S. \& Lancho, J.L. (2018). Long-term effects of Garcinia cambogia/Glucomannan on weight loss in people with obesity, PLIN4, FTO and Trp64Arg polymorphisms. BMC Complementary and Alternative Medicine, 18, 26. DOI: 10.1186/s12906-018-2099-7.

86. Mayer, M.A, Finlayson, G., Fischman, D., de Paz, C., Telleriarte, M.R., Ferrero, A.J., Bobillo, C. \& Fernandez, B.E. (2014). Evaluation of the satiating properties of a nutraceutical product containing Garcinia cambogia and Ascophyllumnodosum extracts in healthy volunteers. Food E Function, 5, 773-779. DOI: 10.1039/c3fo60631g.

87. Sharma, K., Adhikari, D., Kim, H.J., Oh, S.H., Oak, M.H. \& Yi, E. (2019). Citrus junos fruit extract facilitates anti- adipogenic activity of Garcinia cambogia extract in 3T3-L1 adipocytes by reducing oxidative stress. Journal of Nanoscience and Nanotechnology, 19, 915-921. DOI: 10.1166/ jnn.2019.15915.

88. Kim, J., Park, J. \& Lim, K. (2016). Nutrition supplements to stimulate lipolysis: a review in relation to endurance exercise capacity. Journal of Nutritional Science and Vitaminology, 62, 141-161. DOI: $10.3177 / j n s v .62 .141$.

89. Al-Kuraishy, H.M. \& Al-Gareeb, A.I. (2016). Effect of orlistat alone or in combination with Garcinia cambogia on visceral adiposity index in obese patients. Journal of Intercultural and Ethnopharmacology, 5, 408-414. DOI: $10.5455 \%$ 2Fjice.20160815080732.

90. Mahendran, P., Vanisree, A.J. \& Shyamala-Devi, C.S. (2002). The antiulcer activity of Garcinia cambogia extract against indomethacin-induced gastric ulcer in rats. Phytotherapy Research, 16, 8083. DOI: $10.1002 /$ ptr.946.

91. Mahendran, P., Sabitha, K.E. \& Devi, C.S. (2002). Prevention of $\mathrm{HCl}$-ethanol induced gastric mucosal injury in rats by Garcinia cambogia extract and its possible mechanism of action. Indian Journal of Experimental Biology, 40, 58-62. PMID: 12561970 .

92. dos Reis, S.B., de Oliveira, C.C., Acedo, S.C., Miranda, D.D., Ribeiro, M.L., Pedrazzoli, J. Jr. \& Gambero, A. (2009). Attenuation of colitis injury in rats using Garcinia cambogia extract. Phytotherapy Research, 23, 324-329. DOI: 10.1002/ptr.2626.

93. Masullo, M., Menegazzi, M., Di Micco, S., Beffy, P., Bifulco, G., Dal Bosco, M., Novelli, M., Pizza, C., Masiello, P. \& Piacente, S. (2014). Direct interaction of garcinol and related polyisoprenylated benzophenones of Garcinia cambogia fruits with the transcription factor STAT-1 as a likely mechanism of their inhibitory effect on cytokine signaling pathways. Journal of Natural Products, 77, 543-549. DOI: $10.1021 / \mathrm{np} 400804 \mathrm{y}$.

94. Wang, Q.L., Yang, D.Z. \& Lv, C. (2018). Anti-inflammatory effects of gambogic acid in murine collagen-induced arthritis through PI3K/ Akt signaling pathway. Molecular Medicine Reports, 17, 4791-4796. DOI: 10.3892/mmr.2018.8389.

95. Kolodziejczyk, J., Masullo, M., Olas, B., Piacente, S. \& Wachowicz, B. (2009). Effects of garcinol and guttiferone $\mathrm{K}$ isolated from Garcinia cambogia on oxidative/nitrative modifications in blood platelets and plasma. Platelets, 20, 487-492. DOI: $10.3109 / 09537100903165182$.

96. Amin, K.A., Kamel, H.H. \& Abd-Eltawab, M.A. (2011). Protective effect of Garcinia against renal oxidative stress and biomarkers induced by high fat and sucrose diet. Lipids in Health and Disease, 10, 6. DOI: 10.1186/1476-511X-10-6.

97. Sripradha, R., Sridhar, M.G. \& Maithilikarpagaselvi, N. (2016). Antihyperlipidemic and antioxidant activities of the ethanolic extract of Garcinia cambogia on high fat diet-fed rats. Journal of Complementary and Integrative Medicine, 13, 9-16. DOI: 10.1515/jcim2015-0020. 
98. Sripradha, R., Sridhar, M.G. \& Maithilikarpagaselvi, N. (2016). Hydroxycitric acid ameliorates high-fructose-induced redox imbalance and activation of stress sensitive kinases in male Wistar rats. Journal of Basic and Clinical Physiology and Pharmacology, 27, 349-356. DOI: 10.1515/jbcpp-2014-0132.

99. Mazzio, E.A. \& Soliman, K.F. (2009). In vitro screening for the tumoricidal properties of international medicinal herbs. Phytotherapy Research, 23, 385-398. DOI: 10.1002/ptr.2636.

100. Mathew, G.E., Mathew, B., Shaneeb, M.M. \& Nyanthara, B. (2011). Diuretic activity of leaves of Garcinia cambogia in rats. Indian Journal of Pharmaceutical Sciences, 73, 228-230. DOI: 10.4103\% 2F0250-474x.91567.

101. Hayamizu, K., Hirakawa, H., Oikawa, D., Nakanishi, T., Takagi, T., Tachibana, T. \& Furuse, M. (2003). Effect of Garcinia cambogia extract on serum leptin and insulin in mice. Fitoterapia, 74, 267-273. DOI: 10.1016/s0367-326x(03)00036-4.

102. Attia, R.T., Abdel-Mottaleb, Y., Abdallah, D.M., ElAbhar, H.S. \& El-Maraghy, N.N. (2019). Raspberry ketone and Garcinia Cambogia rebalanced disrupted insulin resistance and leptin signaling in rats fed high fat fructose diet. Biomedicine $\mathcal{E}$ Pharmacotherapy, 110, 500-509. DOI: 10.1016/ j.biopha.2018.11.079.

103. Thazhath, S.S., Wu, T., Bound, M.J., Checklin, H.L., Standfield, S., Jones, K.L., Horowitz, M. \& Rayner, C.K. (2016). Effects of intraduodenal hydroxycitrate on glucose absorption, incretin release, and glycemia in response to intraduodenal glucose infusion in health and type 2 diabetes: a randomised controlled trial. Nutrition, 32, 553-559. DOI: 10.1016/j.nut.2015.11.004.

104. Gursel, F.E., Ates, A., Bilal, T. \& Altiner, A. (2012). Effect of dietary Garcinia cambogia extract on serum essential minerals (calcium, phosphorus, magnesium) and trace elements (iron, copper, zinc) in rats fed with high-lipid diet. Biological Trace Element Research, 148, 378-382. DOI: 10.1007/ s12011-012-9385-x.

105. Cheng, I.S., Huang, S.W., Lu, H.C., Wu, C.L., Chu, Y.C., Lee, S.D., Huang, C.Y. \& Kuo, C.H. (2012). Oral hydroxycitrate supplementation enhances glycogen synthesis in exercised human skeletal muscle. British Journal of Nutrition, 107, 1048-1055. DOI: $10.1017 /$ S0007114511003862.

106. Ohia, S.E., Awe, S.O., LeDay, A.M., Opere, C.A. \& Bagchi, D. (2001). Effect of hydroxycitric acid on serotonin release from isolated rat brain cortex. Research Communications in Molecular Pathology and
Pharmacology, 109, 210-216. PMID: 11758650.

107. Thadhani, V.M., Jansz, E.R. \& Peiris, H. (2002). Effect of exogenous histidine and Garcinia cambogia on histamine formation in skipjack (Katsuwonuspelamis) homogenates. International Journal of Food Sciences and Nutrition, 53, 29-34. PMID: 11820094.

108. Kamala, C.T., Chu, K.H., Chary, N.S., Pandey, P.K., Ramesh, S.L., Sastry, A.R. \& Sekhar, K.C. (2005). Removal of arsenic (III) from aqueous solutions using fresh and immobilized plant biomass. Water Research, 39, 2815-2826. DOI: 10.1016/j.watres.2005.04.059.

109. Lee, K.H. \& Lee, B.M. (2007). Evaluation of the genotoxicity of (-)-hydroxycitric acid (HCA-SX) isolated from Garcinia cambogia. Journal of Toxicology and Environmental Health A, 70, 388-392. DOI: 10.1080/15287390600882192.

110. Lau, F.C., Bagchi, M. \& Bagchi, D. (2008). Refuting "Evaluation of the genotoxicity of (-)-hydroxycitric acid (HCA-SX) isolated from Garcinia Cambogia" by Lee and Lee, Journal of Toxicology and Environmental Health, 70:388-392, 2007. Journal of Toxicology and Environmental Health A, 71, 348-349. DOI: 10.1080/15287390701738525.

111. Yu, J.S., Choi, M.S., Park, J.S., Rehman, S.U., Nakamura, K. \& Yoo, H.H. (2017). Inhibitory effects of Garcinia cambogia extract on CYP2B6 enzyme activity. Planta Medica, 83, 895-900. DOI: 10.1055/s-0043-104934.

112. Pittler, M.H. \& Ernst, E. (2004). Dietary supplements for body-weight reduction: a systematic review. The American Journal of Clinical Nutrition, 79, 529-536. DOI: 10.1093/ajcn/79.4.529.

113. Lenz, T.L. \& Hamilton, W.R. (2004). Supplemental products used for weight loss. Journal of the American Pharmacists Association, 44, 59-67. DOI: 10.1331/154434504322713246.

114. Cherniack, E.P. (2008). Potential applications for alternative medicine to treat obesity in an aging population. Alternative Medicine Review, 13, 34-42. PMID: 18377101.

115. Astell, K.J., Mathai, M.L. \& Su, X.Q. (2013). Plant extracts with appetite suppressing properties for body weight control: a systematic review of double blind randomized controlled clinical trials. Complementary Therapies in Medicine, 21, 407-416. DOI: 10.1016/j.ctim.2013.05.007.

116. Kim, J.E., Jeon, S.M., Park, K.H., Lee, W.S., Jeong, T.S., McGregor, R.A. \& Choi, M.S. (2011). Does Glycine max leaves or Garcinia Cambogia promote weight-loss or lower plasma cholesterol in 
overweight individuals: a randomized control trial. Nutrition Journal, 10, 94. DOI: 10.1186/14752891-10-94.

117. Yonei, Y., Takahashi, Y., Hibino, S., Watanabe, M. \& Yoshioka, T. (2008). Effects on the human body of a dietary supplement containing L-carnitine and Garcinia cambogia extract: a study using double -blind tests. Journal of Clinical Biochemistry and Nutrition, 42, 89-103. DOI: 10.3164/jcbn.2008014.

118. Marquez, F., Babio, N., Bullo, M. \& Salas-Salvado, J. (2012). Evaluation of the safety and efficacy of hydroxycitric acid or Garcinia cambogia extracts in humans. Critical Reviews in Food Science and Nutrition, 52, 585-594. DOI: 10.1080/10408398.2010.500551.

119. Heymsfield, S.B., Allison, D.B., Vasselli, J.R., Pietrobelli, A., Greenfield, D. \& Nunez, C. (1998). Garcinia cambogia (hydroxycitric acid) as a potential antiobesity agent: a randomized controlled trial. JAMA, 280, 1596-1600. DOI: 10.1001/jama.280.18.1596.

120. Heber, D. (2003). Herbal preparations for obesity: are they useful? Primary Care, 30, 441-463. DOI: 10.1016/s0095-4543(03)00015-0.

121. Jayawardena, R., Sooriyaarachchi, P., Ranasinghe, P., Perera, A. \& Hills, A.P. (2018). Availability and composition of weight-loss supplements in Sri Lanka. Nutrition $\mathcal{E}$ Dietetics. DOI: 10.1111/17470080.12501.

122. Sharpe, P.A., Granner, M.L., Conway, J.M., Ainsworth, B.E. \& Dobre, M. (2006). Availability of weight-loss supplements: results of an audit of retail outlets in a southeastern city. Journal of American Dietetic Association, 106, 2045-2051. DOI: 10.1016/j.jada.2006.09.014.

123. Jamila, N., Choi, J.Y., Hong, J.H., Nho, E.Y., Khan, N., Jo, C.H., Chun, H.S. \& Kim, K.S. (2016). Identification and quantification of adulteration in Garcinia cambogia commercial products by chromatographic and spectrometric methods. Food Additives and Contaminants: Part A, 33, 1751-1760. DOI: 10.1080/19440049.2016.1244733.

124. Biggs, J.M., Morgan, J.A., Lardieri, A.B., Kishk, O.A. \& Klein-Schwartz, W. (2017). Abuse and misuse of selected dietary supplements among adolescents: a look at poison center data. Journal of Pediatric Pharmacology and Therapeutics, 22, 385393. DOI: 10.5863/1551-6776-22.6.385.

125. Mansi, I.A. \& Huang, J. (2004). Rhabdomyolysis in response to weight-loss herbal medicine. American Journal of Medical Sciences, 327, 356-357. DOI: 10.1097/00000441-200406000-00011.
126. Stevens, T., Qadri, A. \& Zein, N.N. (2005). Two patients with acute liver injury associated with use of the herbal weight-loss supplement hydroxycut. Annals of Internal Medicine, 142, 477-478. DOI: 10.7326/0003-4819-142-6-200503150-00026.

127. Pittler, M.H., Schmidt, K. \& Ernst, E. (2005). Adverse events of herbal food supplements for body weight reduction: systematic review. Obesity Reviews, 6, 93-111. DOI: 10.1111/j.1467789X.2005.00169.x.

128. Actis, G.C., Bugianesi, E., Ottobrelli, A. \& Rizzetto, M. (2007). Fatal liver failure following food supplements during chronic treatment with montelukast. Digestive and Liver Disease, 39, 953955. DOI: 10.1016/j.dld.2006.10.002.

129. Jones, F.J. \& Andrews, A.H. (2007). Acute liver injury associated with the herbal supplement hydroxycut in a soldier deployed to Iraq. American Journal of Gastroenterology, 102, 2357-2358. DOI: 10.1111/j.1572-0241.2007.01353_10.x.

130. Clouatre, D.L. \& Preuss, H.G. (2013). Hydroxycitric acid does not promote inflammation or liver toxicity. World Journal of Gastroenterology, 19, 8160-8162. DOI: $10.3748 \%$ 2Fwjg.v19.i44.8160.

131. Allen, S.F., Godley, R.W., Evron, J.M., Heider, A., Nicklas, J.M. \& Thomas, M.P. (2014). Acute necrotizing eosinophilic myocarditis in a patient taking Garcinia cambogia extract successfully treated with high-dose corticosteroids. Canadian Journal of Cardiology, 30, 1732. DOI: 10.1016/ j.cjca.2014.08.025.

132. Lopez, A.M., Kornegay, J. \& Hendrickson, R.G. (2014). Serotonin toxicity associated with Garcinia cambogia over-the-counter supplement. Journal of Medical Toxicology, 10, 399-401. DOI: 10.1007/ s13181-014-0390-7.

133. Melendez-Rosado, J., Snipelisky, D., Matcha, G. \& Stancampiano, F. (2015). Acute hepatitis induced by pure Garcinia cambogia. Journal of Clinical Gastroenterology, 49, 449-450. DOI: 10.1097/ MCG.0000000000000303.

134. Mancano, M.A. (2015). Garcinia cambogia-induced acute hepatitis; varenicline-induced parkinsonism; resistant hypocalcemia after zoledronic acid administration; zonisamide-induced acute kidney injury; psychosis associated with guanfacine. Hospital Pharmacy, 50, 564-568. DOI: 10.1310/ hpj5007-564.

135. Corey, R., Werner, K.T., Singer, A., Moss, A., Smith, M., Noelting, J. \& Rakela, J. (2016). Acute liver failure associated with Garcinia cambogia use. 
Annals of Hepatology, 15, 123-126. DOI: 10.5604/16652681.1184287.

136. Lunsford, K.E., Bodzin, A.S., Reino, D.C., Wang, H.L. \& Busuttil, R.W. (2016). Dangerous dietary supplements: Garcinia cambogia associated hepatic failure requiring transplantation. World Journal of Gastroenterology, 22, 10071-10076. DOI: $10.3748 \%$ 2Fwjg.v22.i45.10071.

137. Garcia-Cortes, M., Robles-Diaz, M., OrtegaAlonso, A., Medina-Caliz, I. \& Andrade, R.J. (2016). Hepatotoxicity by dietary supplements: a tabular listing and clinical characteristics. International Journal of Molecular Sciences, 17, 537. DOI: $10.3390 /$ ijms17040537.

138. Cotovio, G. \& Oliveira-Maia, A.J. (2017). Hypomania induced by a Garcinia cambogia supplement. Australian and New Zealand Journal of Psychiatry, 51, 641-642. DOI: 10.1177/0004867416667827.

139. Beecheno, M., Budd, S. \& Mohan, T. (2016). Natural weight loss supplements - are they psychoactive? Australian and New Zealand Journal of Psychiatry, 50, 700-701. DOI: $10.1177 \%$ 2F0004867416634869.

140. Bostock, E., Kirkby, K., Garry, M., Taylor, B. \& Hawrelak, J.A. (2018). Mania associated with herbal medicines, other than cannabis: a systematic review and quality assessment of case reports. Frontiers in Psychiatry, 9, 280. DOI: 10.3389/ fpsyt.2018.00280.

141. Bystrak, T., Cervera-Hernandez, M.E., Reddy, N., King, Z. \& Bratberg, J. (2017). Garcinia cambogia, diabetic ketoacidosis, and pancreatitis. Rhode Island Medical Journal, 100, 48-50. PMID: 28968624.
142. Sharma, A., Akagi, E., Njie, A., Goyal, S., Arsene, C., Krishnamoorthy, G. \& Ehrinpreis, M. (2018). Acute hepatitis due to Garcinia Cambogia extract, a herbal weight loss supplement. Case Reports in Gastrointestinal Medicine,

DOI: $10.1155 / 2018 / 9606171$.

143. Kothadia, J.P., Kaminski, M., Samant, H. \& Olivera -Martinez, M. (2018). Hepatotoxicity associated with use of the weight loss supplement Garcinia cambogia: a case report and review of the Literature. Case Reports in Hepatology, DOI: $10.1155 / 2018 / 6483605$.

144. Licata, A. \& Minissale, M.G. (2018). Weight-loss supplementation and acute liver failure: the case of Garcinia Cambogia. Internal and Emergency Medicine, 13, 833-835. DOI: 10.1007/s11739-0181912-0.

145. Crescioli, G., Lombardi, N., Bettiol, A., Marconi, E., Risaliti, F., Bertoni, M., Menniti-Ippolito, F., Maggini, V., Gallo, E., Firenzuoli, F. \& Vannacci, A. (2018). Acute liver injury following Garcinia cambogia weight-loss supplementation: case series and literature review. Internal and Emergency Medicine, 13, 857-872. DOI: 10.1007/s11739-0181880-4.

146. Iqbal, U., Anwar, H., Siddiqui, H.U. \& Mehmood A. (2019). Acute pancreatitis secondary to use of appetite suppressant: Garcinia cambogia. Cureus Journal of Medical Science, 11, 4676. DOI: 10.7759/ cureus.4676.

147. Cho, H.K., Han, Y.S. \& Park, J.M. (2019). Ocular complications of Garcinia cambogia extract diet pills: case report. European Journal of Ophthalmology. $\quad$ DOI: $\quad 10.1177 \%$ 2F1120672119872364. 